\title{
Consciousness and the Unconscious. ${ }^{1}$
}

\author{
By Prof. C. Lloyd Morgan, LL.D., D.Sc., F.R.S.
}

Emergent Evolution.

$\mathrm{B}^{\mathrm{Y}}$ general consent we live in a world in which there seems to be an orderly passage of events. That orderly passage of events, in so far as something new comes on to the scene of Nature, is what I here mean by evolution. If nothing really new emerges-if there be only permutations of what was pre-existent (permutations predictable in advance by some Laplacean calculator)-then, so far, there is no evolution, though there may be progress through survival and spread, on one hand, and elimination on the other. Under Nature is to be included the plan, expressive of natural law, on which all events (including mental events) run their course:

From the point of view of a philosophy based on science our aim is to interpret the natural plan of evolution, and this is to be loyally accepted just as we find it. The most resolute modern attempt to interpret evolution from this point of view is that of Prof. S. Alexander in his "Space, Time, and Deity." He starts from the world of common sense and science as it seems to be given for thought to interpret. In order to get at the very foundation of Nature he bids us think out of it all that can possibly be excluded short of the ttter annihilation of events. That gives us a world of ultimate or basal events in purely spatial and temporal relations. This he calls "spacetime," inseparably hyphened throughout Nature. From this is evolved matter, with its primary and, at a later stage of development, its secondary qualities. Here new relations, other than those which are only spatio-temporal, supervene. Later in logical and historical sequence comes life, a new quality of certain systems of matter in motion, involving or expressing new relations thus far not in being. Then within this organic matrix, already "qualitied" (as he says) by life, there arises the quality of consciousness, the highest that we know. What may lie beyond this in Prof. Alexander's scheme may be learnt from his book.

This thumb-nail sketch can do slight justice to a theme worked out in elaborate detail on a large canvas. The treatment purports to formulate the whole natural plan of ptogressive evolution. From the bosom of space-time emerge the inorganic, the organic, the conscious, and, perchance, something beyond. And with this successive emergence of new qualities goes the progressive emergence of new orders and modes of relatedness. The plan of evolution shows successively higher and richer developments.

Such a doctrine, philosophical in range but scientific in spirit, to which, I may perhaps be allowed to say, I, too, have been led by a rather different route-I call emergent evolution.

1 Abridged from the presidential address delivered to Section J Psychology) of the British Association at Edinburgh on September 9.
The concept of emergence is dealt with by J. S. Mill, in his "Logic," under the consideration of "heteropathic laws." The word "emergent," as contrasted with "resultant," was suggested by G. H. Lewes in his "Problems of Life and Mind." When oxygen, having certain properties, combines with hydrogen having other properties, there is formed water, some of the properties of which are quite different. The weight of the compound is an additive resultant, and can be calculated before the event. Sundry other properties are constitutive emergents, which could not be predicted in advance of any existent example of combination. Of course, when we have learnt what happens in "this" particular instance in "these" circumstances, we can predict what will happen in "that" like instance in similar circumstances. We have learnt" something of the natural plan of evolution. We may also predict on the basis of analogy as we learn to grasp more adequately the natural order or plan of events. But could we predict what will happen prior to any given instance-i.e. prior to the development of this stage of the evolutionary plan? Could we predict life from the plane of the inorganic, or consciousness from the plane of life? In accordance with the principles of emergent evolution we could not do so. The Laplacean calculator is here out of court.

\section{In Mind.}

To come to closer quarters with our sectional topic, what do we mean when we say that this or that is "in mind"? In a well-known passage Berkeley distinguished that which is in mind "by way of attribute" from that which is in mind "by way of idea." Fully realising that this should be read in the light of Berkeley's adherence to the creative concept, one may none the less claim for it validity on the empirical plane where mind is regarded as a product of emergent evolution. The former, therefore (i.e. what is present in mind by way of attribute), I shall speak of as minding, the latter as that which is minded. The former is a character constitutive of the mind-that in virtue of which it is a mind; the latter is objective to the mind or for the mind. That which is minded always implies minding; but it does not necessarily follow that minding implies something minded.

The distinction based on that drawn by Berkeley may be expressed in another way. One may be said to be conscious in perceiving, remembering, and, at large, minding; that which is perceived, remembered, or minded is what one is conscious of. I am conscious in attending to the rhythm or the thought of a poem; I am conscious of that to which I so attend. I need not then be conscious of attending to the poem, though perhaps I may, in psychological mood, subsequently make the preceding process of attention an object of thought. No. 27 II, VOL. IO8] 


\section{Dependence and Correlation.}

On these terms what is minded is no less mental than the process of minding. But I suggest that the word "consciousness" should be reserved for that which Berkeley spoke of as "in mind by way of attribute," or, in Prof. Alexander's way of putting it, as "a quality" of that organism which is conscious in minding. Anyhow, consciousness is here in the world. Creative evolution says: Yes, here in the world, but not of the world. It acts (as élan vital) into or through the organism regarded as a physical system; but its source is i disparate order of being to which, in and for itself, and an sich, it properly belongs. It depends on the physical organism in act but not in being. Now this, I urge, is a metempirical explanation of given facts, but not an empirical interpretation of them as (in my view) science tries to interpret. And its cause should be tried before a different court of appeal from that of science. Hence under emergent evolution one uses the word "dependence" in another sense, and urges that the very being of consciousness, as a quality of the organism, depends upon (or implies the presence of) the quality of life as prior in the natural order of emergence. If we enumerate successive stages, then consciousness is a quality (4) of certain things (very complex and highly organised things) in this world. In these same things there is also present the quality of life (3), and a specially differentiated chemical constitution (2). Empirically we never find (4) without (3), nor (3) without (2); and we express this by saying that consciousness depends on (or implies the presence of) life; and that life depends on a specialised kind of chemical constitution. It is an irreversible order of dependence. But there are things, such as plants, in which we find (as is commonly held) life without consciousness; and other things, such as minerals, in which there is chemical constitution (not, of course, "the same" chemical constitution) without life. Furthermore, there seems to have been a time when consciousness had not yet been evolved; and an earlier time at which life had no existence. But this or that chemical constitution is itself an emergent quality (2) of certain things; and there was probably a yet earlier stage of evolution at which even this quality had not yet emerged-a purely physical stage (I) at which (let us say) electrons afforded the ultimate terms in relation within physical events, continuously changing under electromagnetic (and, of course, also under spatio-temporal) relations.

There is clearly nothing in the foregoing thesis which necessarily precludes the further consideration of the same events from the point of view of creative evolution. The questions: What makes emergents emerge? What directs the whole course of emergent evolution?-these questions and their like are there quite in place. Furthermore, as between emergent thesis and creative antithesis, Kant's "Solution of the Third Antinomy" may afford a guiding clue.

No. 27 I I, VOL. IO8]
The Quality of Consciousness.

Before proceeding further certain preliminary questions must be briefly considered. First, is there progressively emergent evolution in consciousness? It is a question of cardinal importance. My contention is that such evolution obtains in both aspects, inner and outer, the one in correlation with the other. This means that interpretation under emergent evolution is applicable to mental no less than to non-mental events. In other words, there is just as much progressive emergence in the inner or psychical aspect of organic nature as there is in the outer or physiological aspect. This is the keynote of mental evolution throughout its whole range.

I regret here to depart from the conclusion to which Prof. Alexander has been led. Take such episodes in our mental life as seeing a rainbow, hearing a musical chord, partaking of woodcock, dipping one's hands into cool water. In Prof. Alexander's interpretation (as I understand it) percipient consciousness, in each case, differs only in what he speaks of as "direction." That alone is enjoyed. All further difference in one's cognitive experience on these several occasions is due to the difference in that non-mental set of events with which one is then and there compresent. Even feeling, as affective, is not itself enjoyed. Feelings are objective experiences of the order of organic "sensa." They are not in mind by way of attribute. We are conscious of pleasure and pain but are not differentially conscious in receiving them. Consciousness is here just compresent with certain phases of life-process. Thus, for Prof. Alexander, consciousness, alike in sensory acquaintance, in perceptive cognition, and even in feeling pleasure or the reverse, is itself undifferentiated (save in "direction"); all the differentiation is in the non-mental world (beyond us or within our bodies) which is experienced and which transmits its characters to a recipient in which the rather featureless quality of consciousness has emerged.

\section{Consciousness and Enjoyment.}

Thus far the word "conscious" is used in the broad and comprehensive sense that was almost universally accepted a generation ago. But in accordance with current usage we must now distinguish consciousness from the unconscious. I happen to regard the word "unconscious" as peculiarly unfortunate-chosen as it is on the lucus a non lucendo principle. But let that pass. There it is and we must make the best of itseeking to penetrate its dark wood. Under the older and more comprehensive use, consciousness may be indefinable. As in the case of spatial or of temporal relatedness we have got down to something that we find, rather than to something that can be strictly defined. Hence one has to proceed by indicating instances that fall within the inclusive class which we so name. The position is that, in the comprehensive class which we used to comprise under the heading of conscious: 
ness, it is now thought desirable to make two sub-classes- $(a)$ the unconscious and $(b)$ the conscious. There is call, therefore, for the indication of some criteria which shall serve to distinguish the one from the other. Here definition is required. And since the unconscious is "served with the negative prefix," it is clear that the criteria we seek must distinguish by their presence the conscious from the unconscious in which these criteria are absent. Under what heading, then, are we now to place the comprehensive class including both $(a)$ and $(b)$ ? I suppose we may call it the class of psychical events-as distinguished from physical and physiological events. But we still want some convenient noun which we may qualify by the adjectives "conscious" and "unconscious." I borrow from Prof. Alexander, and adapt for my present purpose, the name "enjoyment." Perhaps the chief objection to the choice of this word is that it must be understood as including what is unpleasant no less than that which is pleasurable. But as I cannot find a better, and am loth to coin a worse, I ask leave to use this word "enjoyment" to include all that has the psychical character or aspect. I regard the emphasis on affective tone which it suggests as a point in its favour.

On these terms there fall within the comprehensive class of enjoyment two sub-classes: (a) unconscious enjoyment and (b) conscious enjoyment-the latter marked by certain differentiating criteria. The question now arises: Is the distinction between the conscious and the unconscious just the same as that which is often drawn between "above the threshold" and "below the threshold" (supraliminal and subliminal)? Or, if they are not just the same, is there such close and intimate alliance that we may still say that all that is supraliminal is conscious and all that is subliminal is unconscious? What I wish to suggest is that the line between supraliminal and subliminal need not be coincident with that between conscious and unconscious. There are, I believe, modes of enjoyment both conscious and unconscious in the supraliminal field. But this reopens the main question: What are the differentiating criteria of the conscious?

\section{Criteria of Consciousness.}

Ask the plain man what he means when he speaks of acting consciously and he will probably reply: "I mean doing this or that with some measure of intention and with some measure of attention to what is done or to its outcome. The emphasis may vary; but one, or other, or both, of these characterise action that $I$ call conscious. If I offend a man unconsciously there is no intention to give offence. When a cyclist guides his machine unconsciously he no longer pays attention to the business of steering, avoiding stones in the road, and so forth." Now if this correctly represents the plain man's view, it is clear that a full consideration of his attitude would involve careful discussion of intention and of attention.
This is beyond my present scope. I want to dig farther down so as to get at what, as I think, underlies his meaning, and thus to put what 1 have to submit in a much more general form.

I want, if possible, to get down to what there is in the most primitive instances of consciousness -i.e. right down to that which characterises them as such. I believe that there is always in addition to that which is immediately given (say under direct stimulation in sense-awareness) some measure of revival with expectancy, begotten of previous behaviour in a substantially similar situation. Consciousness is always a matter of the subsequent occasion, and always presupposes a precedent occasion. In other words it is the outcome of repetition; and yet, paradoxically, when it comes it is something genuinely new. But this is the very hall-mark of emergence. 'That is why Prof. Alexander and I speak of consciousness as an emergent quality.

Let us analyse some simple first occasion-that on which a chick behaves to a ladybird will serve. The eye is stimulated from a distance with accompanying enjoyment (a). The chick responds by approaching and pecking with enjoyment in behaving $(b)$. There follows contact stimulation with its enjoyment $(c)$; and, thereon, behaviour of rejection with its enjoyment $(d)$. We have thus, as I interpret, a biologically determined but orderly sequence affording successive modes of enjoyment $a, b, c, d$. So far the precedent occasion. On a subsequent occasion there is $(a)$ as before in presentative form; this is immediately given in sensory acquaintance. But $(b, c, d)$ are also "in mind "-mediately or in re-presentative guise, under revival, as what Prof. Stout calls "meaning." We have therefore (under an analogy) on the precedent occasion the notes $a, b, c, d$, struck in sequence. We have on the subsequent occasion $(b, c, d)$ rung up by $(a)$ through a "mechanism" provided psychically and neurally in the instrument. And when the notes $(a, b, c$, d) thus vibrate together they have the emergent quality of what one may speak of as the chord of consciousness.

What is there, however, about this emergent chord which differentiates it from the precedent sequence of notes $a, b, c, d$ ? It must be something psychical in its nature. I suggest that the revival carries with it a specific mode of new enjoyment which may be called "againness"; that which affords the basis of felt recognition. There is also something equally new in expectancy. That this is (so far as our own experience testifies) a factor in the chord of consciousness is, I should suppose, scarcely open to question.

Now whereas on the precedent occasion it is behaviour unconsciously directed towards that from which stimulation arrives that determines the order $b, c, d$ as sequent on $a$, on the subsequent occasion it is the "meaning" $(b, c, d)$ which then consciously determines the direction of behaviour. This centering of "meaning" on that NO. 27 I I, VOL. IO $_{\text {J }}^{\text {J }}$ 
to which behaviour was on the precedent occasion unconsciously directea is the basis of conscious reference to an object.

The characteristics, then, of a chord of consciousness are revival with expectancy and with conscious reference which anticipates, and, through anticipation (thus forestalling the event), may endorse or inhibit, the further course of behaviour. And its emergent character, as chord, makes consciousness, not merely an additive bleno of constituent tones of enjoyment, but (in Browning's forcible emphasis on a wholly new quality) "a star." (Cf, Abt Vogler.)

I have thus far dealt with the criteria of consciousness on the lines of what I conceive to be its evolutionary genesis. I must now ask whether these criteria-revival with expectancy and reference-do not characterise what we commonly regard as conscious enjoyment in our own adult life. My own experience is consonant with the outcome of genetic treatment. And I would ask others if there is not in our current consciousness always some measure of felt "againness" carried over from the past in revival, and always some measure of "comingness" in expectancy. I would ask whether there is not, as essential to consciousness, some leaning back on previous experience, some leaning forward to that which the future has in store. Is not this what M. Bergson means (I do not say all that he means) when he speaks of consciousness as "a hyphen" linking past and future?

\section{Levels of Psychical Integration.}

In our normal life much integration proceeds on the reflective level-that of rational thought and volitional conduct. The older philosophers, with some variation of terminology, urged that the difference between this reflective level and the perceptive level below it (e.g. in Descartes's animal automatism) is one not only of degree but of kind. The difference, they said in effect, is radical and absolute, demanding metempirical explanation. Thus the word "kind" carried a definitely metaphysical implication the influence of which is still with us to-day. But apart from this, as a matter of frankly empirical description of what is found, it was their way of expressing what I seek to express by saying that reflective consciousness has a new emergent quality-that which characterises reason as distinguished from perceptual intelligence. We have, however, the one word "consciousness" for both these levels. But within the more comprehensive sub-class, comprising all instances of consciousness, we may distinguish two sub-classes subordinate therein, (i) that of instances of reflective consciousness, and (ii) that of instances of non-reflective consciousness. Both sets of instances have the criteria of consciousness. But in (i) there is a further differentia in that "value" (in the technical sense) is referred to the object of such reflective thought. There is then, on this view, reflective integration, and there is also nonNo. 27 I I, VOL. I08] reflective or perceptive integration, each on its appropriate level, and each in its distinctive way conscious.

In dealing with the supraliminal field it seems to me imperative to distinguish according to the mode of origin of the integration that obtains therein. We must ask: How far is the "form" which it assumes (iii) the outcome of reflective integration; (ii) the outcome of unreflective or perceptive integration; and (i) the outcome of the integration in the subliminal unconscious to which as living beings we are heirs? If I am right in regarding (ii) and (iii) as successively emergent qualities of consciousness there is somewhat of a leap (though no breach of continuity) from (i) to (ii), and from (ii) to (iii). There is always something more (involving new terms in new relations) in the higher-level conclusion than is contained in the lower-level premises. This is the cardinal principle of all emergent evolution. Without this there would be nothing really newmerely a reshuffling of the old.

\section{Are there Unconscious Images and Ideas?}

In the interpretation to which I have been led unconscious enjoyment (not necessarily involving. unconscious images and ideas) is no less integrated than is the system of physiological events which gives to life its emergent quality. If the analogy be permitted, just as in the physiological symphony of life there are chords and phrases and motifs, each with an emergent character of its own (e.g. the part played by the instruments of the reproductive sub-system), so too, in the psychical symphony of unconscious enjoyment there are correlated chords, phrases, and motifs. And all goes well so long as due balance and harmony are maintained in the orchestral performance, no matter what instruments play a dominant part at the time being. But unconscious enjoyment is primarily inherited psychical music correlated with the outcome of life-inheritance. I entertain little doubt that the life of animals, could we only feel its inner aspect as they themselves do, is brim-full of a rich music of unconscious enjoyment. As I write the swifts are wheeling and shrilling in the summer air. Am I wholly wrong in imputing to them an integrated form of enjoyment which is theirs on a basis of inheritance? Perhaps even sympathetic naturalists fail adequately to realise to what extent in animals the business of life as such, with further life as its wage, has also its psychical reward in enjoying so fully the performance of life's job. And this reward in the enjoyment of doing is inherited with the ability to do. A behaviourist interpretation of how it all comes about is, I believe, perfectly sound in its way. Not in what it emphasises, but in what (among extremists) it ignores-a psychical factor-does it seem to me to be deficient. In us at any rate the presence of enjoyment is undeniable. And though it is so readily caught up into consciousness it still carries, I think, the marks of its unconscious origin. 
What does the poet or the artist tell us? Does he not claim that what springs up within him-if it be in truth (he may add) in any valid sense his -is quite inexplicable on what he regards as psychological principles? And if psychological principles deal only with conscious integration he is right. His poetry, or his art, is not in its essential nature the outcome of perceptive or reflective integration. Its well-springs lie deeper than that in the unconscious. He rightly affirms that the real thing in all true art is beyond his conscious control, though the means by which it is expressed must be learnt and may be bettered by taking thought. This is enshrined in the proverb : Poeta nascitur non fit. And even of those who can only appreciate his work, may it not be said, with a touch of paradox, that enjoyment in art becomes reflectively conscious in criticism? This need not mean that the critic enjoys poetry any the less for the combination in higher integration of unconscious and conscious enjoyment. What it does mean is that the glad newness and glory of surprise lies in the poetry and not in the criticism. Once again it must be said that it is the fresh unexpectedness that is still the hall-mark of the unconscious.

\section{The Age of the Earth.}

A LTHOUGH it cannot be claimed that the A joint discussion on the "Age of the Earth," at the meeting of the British Association at Edin. burgh on September I3, led to the complete reconciliation of the views of the various sections of the Association represented, there could be no doubt concerning the extraordinary interest taken in it. Members desiring admission overtaxed the capacity of one of the largest lecture theatres in Edinburgh, and shortly after the all too short discussion one might overhear in the streets of the city the remark, "They haven't settled it yet." It was quite evident that it was a good thing, if merely for the dissemination of modern views on the subject, that authoritative representatives of each science should address the same composite audience of physicists, geologists, biologists, and many who would claim none of these descriptions.

It was not surprising that the starting point of all the speakers was the inadequacy of Lord Kelvin's estimate of twenty million years for the age of the sun. Lord Rayleigh, whose lucid opening of the discussion will long be remembered, evidently believed that Kelvin had covered his estimate sufficiently with the proviso concerning sources of solar energy other than gravitation. Such sources, i.e. radio-active materials, Kelvin was unaware of, but we now know them to exist in the earth, and must presume them also to exist in the sun. Lord Rayleigh proceeded to develop his argument for arriving at the age of uranium-bearing rocks from considerations of the uranium-lead and helium which they now contain. The order and rate of radioactive disintegration through the series from uranium to lead are known with considerable precision; helium also is evolved at a definite ascertained rate. An examination of the amount of lead now present in uranium minerals enables the time when disintegration commenced to be specified, for the lead in the rocks in question proves to be not ordinary lead but wholly that isotope of atomic weight 206 which is necessarily associated with the decay of uranium. Thus broggerite found in the pre-Cambrian rocks at Moss, Norway, contains lead of atomic weight NO. $27 \mathrm{II}$, vOL. IO8]
206.06; the lead-uranium ratio is O.II 3 , and this points to an age of 925 million years, upon the assumption that uranium and its products have always decayed as they do now. Estimates of age can also be made by measuring the content in rocks of that other product of disintegrationhelium-although leakage of this gas makes the calculation less reliable. Allowing for this, however, the indications by helium content are generally confirmatory of those given by the leaduranium ratio. These methods can be applied to younger formations of rocks, thus obtaining the approximate age of each.

Lord Rayleigh pointed out that Prof. H. N. Russell, by applying the argument statistically to the earth's crust as a whole, arrived at the period $8 \times 10^{9}$ years as an upper limit-this being six times longer than that of any individual rock yet examined. He concluded by giving a period amounting to a moderate multiple of IOoO million years as the probable duration of the earth's crust in a condition suitable for the habitation of living beings. The radio-active investigations leading to this conclusion are supported by other physical and astronomical evidence.

Prof. Sollas, who followed, made merry on behalf of the geologist, "newly enriched" from a "bankrupt" with a " mere score of millions of years" to a "bloated capitalist-with more millions in the bank than he knew how to dispose of." Within broad limits, he said, geologists were ready: to leave to the physicists the precise calculation of geological time. Some geologists, notably the brilliant and lamented Barrell, had already begun to rebuild their science on the magnified scale. For himself, he preferred first " to make sure that the new radio-active clock was not as much too fast as Lord Kelvin's was too slow." In this connection Prof. Sollas directed attention to Prof. Joly's examination of the "pleochroic haloes" occurring in uranium-bearing black mica. These haloes, which are formed by the $a$-rays expelled by uranium in the various stages of its disintegration, are found generally to have ranges consistent with those obtaining in modern times. The two inner rings, however, form a notable exception, indicating ranges greater than normal 